\title{
Knowledge, attitudes and practices regarding postpartum contraception among 100 mother-father pairs leaving a Sri Lankan maternity hospital after childbirth
}

(Index words: Antenatal education, induced abortion, male participation, postpartum contraception)

An estimated seven induced abortions take place for every 10 births in Sri Lanka [1]. The main reason for seeking an abortion is that the youngest child is too young [2], indicating a deficiency in family planning in the postpartum period and in families with young children. In Sri Lanka, $96 \%$ of the deliveries take place in hospitals [3]. There are, therefore, many opportunities to introduce the subject of postpartum contraception.

We studied the knowledge, attitudes and intended practice of postpartum contraception among a group of 100 mother-father couples leaving the De Soysa Hospital for Women, Colombo, after childbirth. A pre-tested questionnaire was administered by an interviewer to each participant.

Sixty four (64\%) mothers and $76(76 \%)$ fathers had had at least 10 years of school education. Thirty seven $(37 \%)$ of the couples had previously used modern methods of contraception. Twenty eight (28\%) of mothers and 41 $(41 \%)$ of fathers had not decided on a method of postpartum contraception at the time of interview. Only $28 \%$ of the fathers had received education about contraception during the index pregnancy compared to $76 \%$ of the mothers.

Fifty one per cent of the mothers received information from the field clinics, $33 \%$ from the field midwife and $46 \%$ from the prenatal classes at the De Soysa Hospital. Nineteen per cent of the fathers received information from these classes, and contributions from other sources was negligible.

All 76 mothers who had received information knew about methods available for use and $85.5 \%$ knew about their side-effects. However, knowledge regarding follow up $(40.8 \%)$ and danger signs (22.4\%) was poor. Among the 28 fathers who had received information, the figures were lower at $25 \%$ and $14.3 \%$, respectively. Only 39 (39\%) of the mothers and $7(7 \%)$ of the fathers were aware of the necessity to start a contraceptive method by 6 weeks' postpartum. Twenty-six (26\%) of mothers and 43 (43\%) of the fathers were unaware that it was possible to conceive before the return of periods. Seventy six $(76 \%)$ and 72 (72\%) of mothers and fathers, respectively, knew that it was possible to conceive during lactation.

This study shows poor awareness regarding some vital aspects of postpartum contraception and, in particular, that there is little effort to educate fathers. Sri Lankan men play an important role in decisions regarding contraception [4]. Improvement of education regarding postpartum contraception could contribute to reducing the high abortion rate in Sri Lanka.

\section{References}

1. Rajapaksha LC. Estimates of abortion in urban and rural Sri Lanka. Journal of the College of Community Physicians of Sri Lanka 2002; 7: 10-6.

2. Rajapaksha LC., De Silva I. A profile of women seeking abortion. A publication of the Department of Community of Medicine, University of Colombo, Sri Lanka, 2000.

3. Sri Lanka Demographic and Health Survey 2003. Department of Census and Statistics in collaboration with Ministry of Health, Nutrition and Welfare, Sri Lanka.

4. De Silva P. Male influence on female contraception. In: Family Planning: Meeting Challenges, Promoting Choices. IPPF International Family Planning Congress, New Delhi, 1992, pp 579-82.

Hemantha Senanayake, Senior Lecturer, and SA Seneviratne and Viraj Kariyawasam, Research Assistants, Department of Obstetrics and Gynaecology, Faculty of Medicine, University of Colombo, Sri Lanka.

Correspondence: HS, e-mail: < senanayakeh@gmail.com>. (Competing interests: none declared). Received 19 October 2005 and revised version accepted 18 November 2005 